\title{
Influence of Crystallite Size on the Magnetic Order in Semiconducting $\mathrm{ZnCr}_{2} \mathrm{Se}_{4}$ Nanoparticles
}

\author{
Ewa Malicka ${ }^{1}$, Małgorzata Karolus ${ }^{2, *}$, Tadeusz Groń ${ }^{3}$, Adrian Gudwański ${ }^{1}$ (1), \\ Andrzej Ślebarski ${ }^{3}{ }^{\circledR}$, Jerzy Goraus ${ }^{3}$, Monika Oboz ${ }^{3}{ }^{\circledR}$, Bogdan Sawicki ${ }^{3}$ and Joanna Panek ${ }^{2}$ \\ 1 Institute of Chemistry, University of Silesia, 40-007 Katowice, Poland; ewa.malicka@us.edu.pl (E.M.); \\ agudwanski@gmail.com (A.G.) \\ 2 Institute of Material Science, University of Silesia, 40-007 Katowice, Poland; joanna.panek@us.edu.pl \\ 3 Institute of Physics, University of Silesia, 40-007 Katowice, Poland; tadeusz.gron@us.edu.pl (T.G.); \\ andrzej.slebarski@us.edu.pl (A.Ś.); jerzy.goraus@us.edu.pl (J.G.); monika.oboz@us.edu.pl (M.O.); \\ bogdan.sawicki@us.edu.pl (B.S.) \\ * Correspondence: karolus@us.edu.pl
}

Received: 24 October 2019; Accepted: 26 November 2019; Published: 28 November 2019

\begin{abstract}
Structural, electrical, magnetic, and specific heat measurements were carried out on $\mathrm{ZnCr}_{2} \mathrm{Se}_{4}$ single crystal and on nanocrystals obtained from the milling of this single crystal after 1, 3, and $5 \mathrm{~h}$, whose crystallite sizes were 25.2, 2.5, and $2 \mathrm{~nm}$, respectively. For this purpose, the high-energy ball-milling method was used. The above studies showed that all samples have a spinel structure, and are $p$-type semiconductors with less milling time and $n$-type with a higher one. In turn, the decrease in crystallite size caused a change in the magnetic order, from antiferromagnetic for bulk material and nanocrystals after 1 and $3 \mathrm{~h}$ of milling to spin-glass with the freezing temperature $T_{\mathrm{f}}=20 \mathrm{~K}$ for the sample after $5 \mathrm{~h}$ of milling. The spin-glass behavior for this sample was derived from a broad peak of dc magnetic susceptibility, a splitting of the zero-field-cooling and field-cooling susceptibilities, and from the shift of $T_{\mathrm{f}}$ towards the higher frequency of the ac susceptibility curves. A spectacular result for this sample is also the lack of a peak on the specific heat curve, suggesting a disappearance of the structural transition that is observed for the bulk single crystal.
\end{abstract}

Keywords: nanoparticles; semiconductors; antiferromagnetic; spin-glass; specific heat

\section{Introduction}

The search for new materials for applications in thermoelectric devices is becoming more and more popular. Seleno-spinels are interesting compounds useful for this purpose [1-3], possessing a large cubic cell with an edge of $10 \AA$, a large ion radius of selenium (198 pm [4]), and strong covalence [5]. Pure $\mathrm{ZnCr}_{2} \mathrm{Se}_{4}$ in both mono and polycrystalline form is a $p$-type semiconductor, has a helical antiferromagnetic structure (AFM) below the Néel temperature $T_{\mathrm{N}}=20 \mathrm{~K}$, and a strong ferromagnetic component (FM), as evidenced by the high positive Curie-Weiss temperature $(\theta)$ of $115 \mathrm{~K}[6,7]$. At $T_{\mathrm{N}}$ temperature, there is a structural phase transition from cubic $F d-3 m$ to tetragonal symmetry $I_{1} /$ amd with slight contraction along the $c$ axis [8,9]. $\mathrm{ZnCr}_{2} \mathrm{Se}_{4}$ is a normal spinel in which zinc ions occupy tetrahedral sites and chromium ions occupy octahedral ones. Replacing one element with another or adding another element can strongly affect the physico-chemical properties of the matrix [10-14].

Recently, a $\mathrm{CuCr}_{2} \mathrm{~S}_{4}$ spinel was obtained from pure elements $\mathrm{Cu}, \mathrm{Cr}$, and $\mathrm{S}$ by mechanical alloying (MA), whose crystallite size was on the order of $2.8 \mathrm{~nm}$ [15]. This method showed that, instead of the classic metallic ferromagnet, we received an antiferromagnetic semiconductor also with a spinel structure. Moreover, spin frustration for further $\mathrm{Cr}-\mathrm{Cr}$ ion coordination spheres was observed [15]. 
In the present work, we obtained $\mathrm{ZnCr}_{2} \mathrm{Se}_{4}$ nanopowders, by the high-energy ball-milling method, from the milling of the $\mathrm{ZnCr}_{2} \mathrm{Se}_{4}$ single crystal after 1, 3, and $5 \mathrm{~h}$. Structural, magnetic, electronic transport, and specific heat studies were carried out on the single crystal and nanopowder samples. We expect these studies to show that obtaining nanoscale $\mathrm{ZnCr}_{2} \mathrm{Se}_{4}$ crystallites will significantly change their physical properties.

\section{Materials and Methods}

The nanosized crystallites of $\mathrm{ZnCr}_{2} \mathrm{Se}_{4}$ spinel were made with the use of the high-energy ball-milling (HEBM) method. The starting materials for the HEBM method were single crystalline samples to avoid impurity phases, whose lack was confirmed by powder X-ray diffraction studies.

Single crystals of $\mathrm{ZnCr}_{2} \mathrm{Se}_{4}$ were grown by chemical vapor transport technique with the anhydrous chromium chloride as the carrier agent. A stoichiometric mixture of the selenide $\mathrm{ZnSe}$ and transporting agent $\mathrm{CrCl}_{3}$ were enclosed in evacuated $\left(\sim 10^{-3} \mathrm{~Pa}\right.$ ) and sealed quartz ampoules (a length of about $200 \mathrm{~mm}$ and an inner diameter of $20 \mathrm{~mm}$ ). The ampoules were heated in a two-zone gradient furnace for 3 weeks. The optimal temperatures at the crystallization and melting zones were between 1123 and $1223 \mathrm{~K}$, respectively. The right choice of transport conditions resulted in obtaining good quality octahedral crystals with surface types (111).

Milling was carried out in PULVERISETTE 7 premium line Planetary Ball Mill (Fritsch, Germany) at room temperature with stainless steel vessels and balls $(5 \mathrm{~mm})$. Single crystals were milled up to $5 \mathrm{~h}$ at the speed of $500 \mathrm{rpm}$ with a 10:1 ball-to-crystals ratio in dry conditions. Milling of single crystals was carried out under a protective argon (Ar) atmosphere.

The powders obtained after 1, 3, and $5 \mathrm{~h}$ of milling were characterized by $\mathrm{X}$-ray diffraction technique (Empyrean, PANalytical, Almelo, Netherlands) and scanning electron microscopy (SEM).

The X-ray diffraction experiment was performed with the Empyrean PANalytical Diffractometer with copper radiation $\left(\lambda C \mathrm{u}_{\mathrm{K} \alpha}=1.5418 \AA\right)$ and PIXcel counter. The phase analyses were performed with the ICDD PDF4+ 2017 crystallographic database. The determination of unit cell parameters, crystallite sizes, and lattice strain values, as well as qualitative phase analysis, were refined by the use of the High Score Plus PANalytical software (HSP version 3.0, PANalytical, Almelo, Netherlands) based on the Williamson-Hall theory [16] and Rietveld refinement [17,18]. The scheme of analyses, conditions, and accuracy of methods were presented in detail in, among other works $[19,20]$.

The morphology of the powders was studied by the use of a scanning electron microscope (SEM) (Jeol JSM-6480) (JEOL Ltd, Tokyo, Japan).

The electrical conductivity $\sigma(\mathrm{T})$ was measured in the $74-410 \mathrm{~K}$ temperature range using the dc method and KEITHLEY 6517B Electrometer/High Resistance Meter (Keithley Instruments, LLC, Solon, $\mathrm{OH}, \mathrm{USA}$ ). The thermoelectric power $S(\mathrm{~T})$ was measured in the temperature range of 100-400 K by a Seebeck Effect Measurement System (MMR Technologies, Inc., San Jose, CA, USA). The static dc magnetic susceptibility was measured in both the zero-field cooled (ZFC) and the field-cooled (FC) modes in the magnetic field $H_{\mathrm{dc}}=1 \mathrm{kOe}$. The calculations of the effective magnetic moment, and the method of preparation of powder samples for measurements of electrical conductivity and thermopower, are described in detail in [15,21-23]. Magnetization isotherms were measured at 2, 10, 20, 40,60 , and $300 \mathrm{~K}$ in applied external fields up to $70 \mathrm{kOe}$. Magnetization and dc magnetic susceptibility were carried out in the temperature range of 2-300 K using a Quantum Design MPMS-XL-7AC SQUID magnetometer (Quantum Design, San Diego, CA, USA). For ac magnetic susceptibility in the frequency range $300 \mathrm{~Hz}-10 \mathrm{kHz}$, and with specific heat measurements, a Quantum Design Physical Properties Measurement System (QD-PPMS) (Quantum Design, San Diego, CA, USA) was used. The superexchange integrals for the first two coordination spheres $J_{1}$ and $J_{2}$ were calculated with the aid of the Holland and Brown equations: $J_{1}=\left(-9 T_{\mathrm{N}}+\theta\right) / 60$ and $J_{2}=\left(3 T_{\mathrm{N}}+\theta\right) / 120$ [24]. The exchange constant $J_{\mathrm{SG}}$ of the spin-glass system was estimated using the random energy model [25-27] by the expression: $J_{\mathrm{SG}}=\mathrm{T}_{\mathrm{f}} \cdot(4 \cdot \ln 2)^{1 / 2}[25]$. 


\section{Results and Discussion}

\subsection{Structural Characteristics}

X-ray diffraction patterns analysis (Figure 1) indicated the presence of spinel $\mathrm{ZnCr}_{2} \mathrm{Se}_{4}(\mathrm{Fd}-3 \mathrm{~m})$ in all samples (ICDD PDF4+ 2017: 03-065-0689). Structural analysis carried out by the use of the Rietveld procedure allowed the determination of lattice parameters of nanocrystalline spinel after a specified milling time and its size of crystallites and lattice strains (Table 1). During the milling process, the size of spinel $\mathrm{ZnCr}_{2} \mathrm{Se}_{4}$ crystallites decreased from $25.2 \mathrm{~nm}$ (for $1 \mathrm{~h}$ ), then $2.5 \mathrm{~nm}$ (for $1 \mathrm{~h}$ ) to $2 \mathrm{~nm}$ (for $5 \mathrm{~h}$ ) (Table 1). The significant change of lattice strain $(\tau)$ value obtained after $5 \mathrm{~h}$ of milling and visible change of peak intensities (e.g., $2 \theta=28,32$ diffraction line) might indicate the unit cell deformation and appearance of texture in the material. The refinement parameters obtained during the analysis process reached acceptable [17-20] levels of: $R_{\exp }=5.1-10.7 \% ; R_{p}=5.8-12.1 \% ; R_{w p}=7.5-10.1 \%$; and goodness-of-fit $(\mathrm{S})=1.7-1.9$.

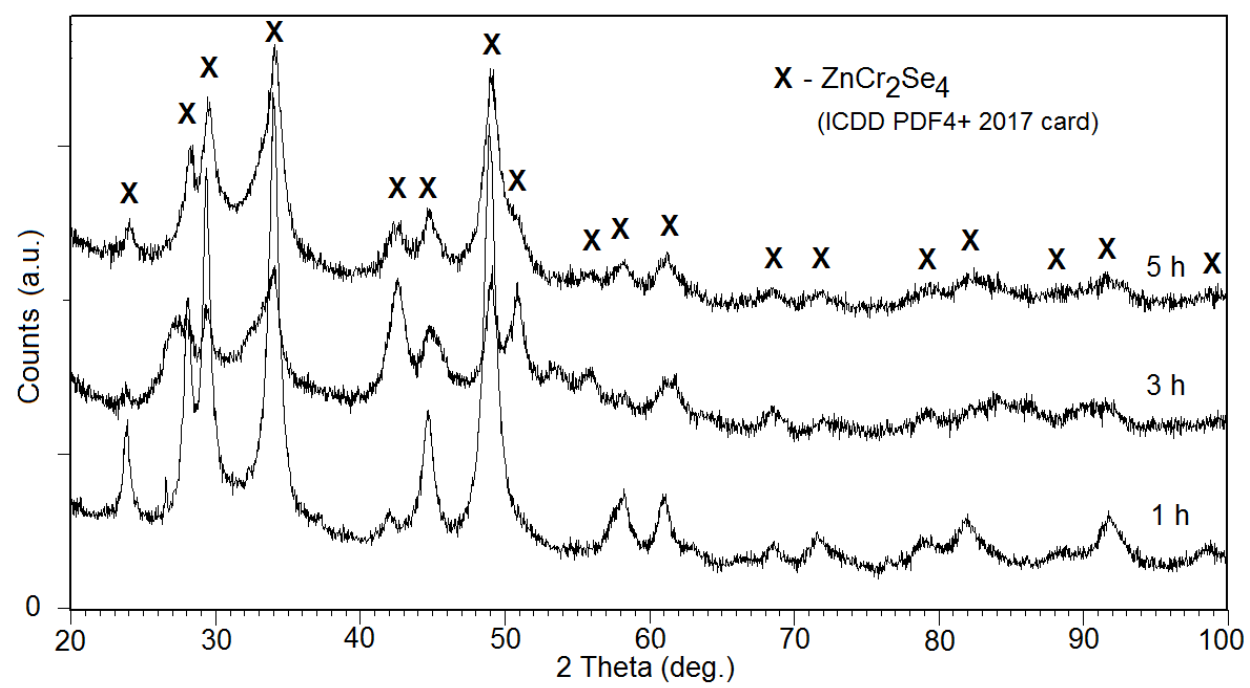

Figure 1. The X-ray diffraction patterns of spinel $\mathrm{ZnCr}_{2} \mathrm{Se}_{4}$ (ICDD PDF4+ 2017: 03-065-0689 card) after 1,3 , and $5 \mathrm{~h}$ of milling.

Table 1. Structural parameters of $\mathrm{ZnCr}_{2} \mathrm{Se}_{4}$ nanospinel.

\begin{tabular}{cccc}
\hline $\begin{array}{c}\boldsymbol{t} \\
\mathbf{( h )}\end{array}$ & $\begin{array}{c}\boldsymbol{a} \\
(\mathbf{\AA})\end{array}$ & $\begin{array}{c}\boldsymbol{d} \\
(\mathbf{n m})\end{array}$ & $\begin{array}{c}\boldsymbol{\tau} \\
\mathbf{( \% )}\end{array}$ \\
\hline 1 & $10.5064(5)$ & $25 .(2)$ & 0.8 \\
3 & $10.4856(4)$ & $2 .(5)$ & 1.1 \\
5 & $10.4758(3)$ & $2 .(0)$ & 1.3 \\
\hline
\end{tabular}

$t$ is the milling time, $a$ is the unit cell parameter, $d$ is the crystallite size, and $\tau$ is the lattice strain. For comparison, the theoretical unit cell parameter of $\mathrm{ZnCr}_{2} \mathrm{Se}_{4}$ bulk spinel $(\mathrm{a}=10.4970 \AA$ ) was taken from the ICDD PDF4+ 2017: 03-065-0689 card.

SEM images of the investigated $\mathrm{ZnCr}_{2} \mathrm{~S}_{4}$ powder after milling for $5 \mathrm{~h}$, presented in Figure 2, showed morphology typical of materials subjected to high-energy ball-milling. Repeated processes occurring during milling lead to the formation of small particles. The formation of smaller or larger agglomerates, consisting of submicro-sized or nanosized particles, was an effect of crushing and subsequent agglomeration by cold welding, fracturing, and re-welding. The particles visible in the SEM images represent grains and their agglomerates of various sizes, from 0.1 to $2 \mu \mathrm{m}$. 

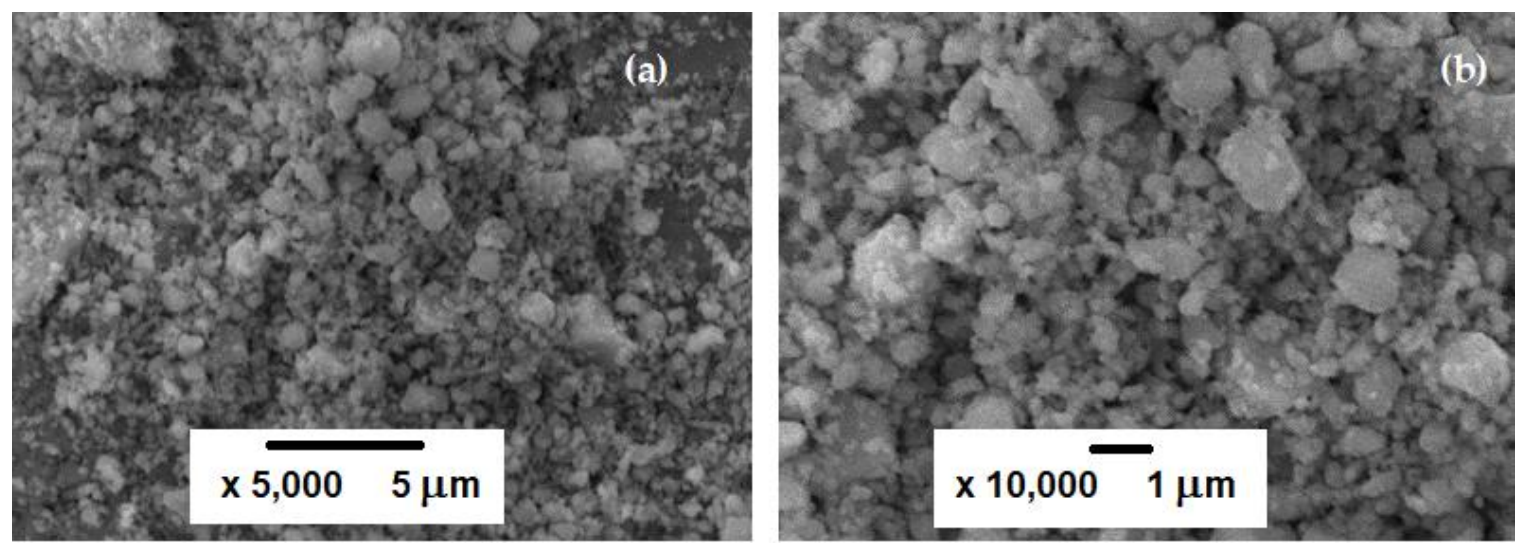

Figure 2. SEM images of $\mathrm{ZnCr}_{2} \mathrm{Se}_{4}$ powder after $5 \mathrm{~h}$ of milling magnified (a) 5,000 times and (b) 10,000 times.

\subsection{Electrical Properties}

The electrical conductivity $(\sigma)$ measurements of single crystal and nanocrystals after 1 and $5 \mathrm{~h}$ of milling, displayed in Figure 3, showed semiconducting behavior. As the crystallite size decreased, the electrical conductivity decreased in the measured temperature range. The electrical conductivity of all samples was thermally activated, and activation energy $\left(E_{\mathrm{A}}\right)$ slightly increased in the extrinsic region from $0.05 \mathrm{eV}$ (for bulk), then $0.06 \mathrm{eV}$ (for $1 \mathrm{~h}$ ) to $0.07 \mathrm{eV}$ (for $5 \mathrm{~h}$ ). In the intrinsic region, $E_{\mathrm{A}}$ changed from $0.22 \mathrm{eV}$ (for bulk), then $0.10 \mathrm{eV}$ (for $1 \mathrm{~h}$ ) to $0.14 \mathrm{eV}$ (for $5 \mathrm{~h}$ ). A much smaller $E_{\mathrm{A}}$ of nanoparticles in the intrinsic region compared to a bulk material may be the result of the formation of agglomerates composed of submicro-sized or nanosized particles, visible on the SEM image.

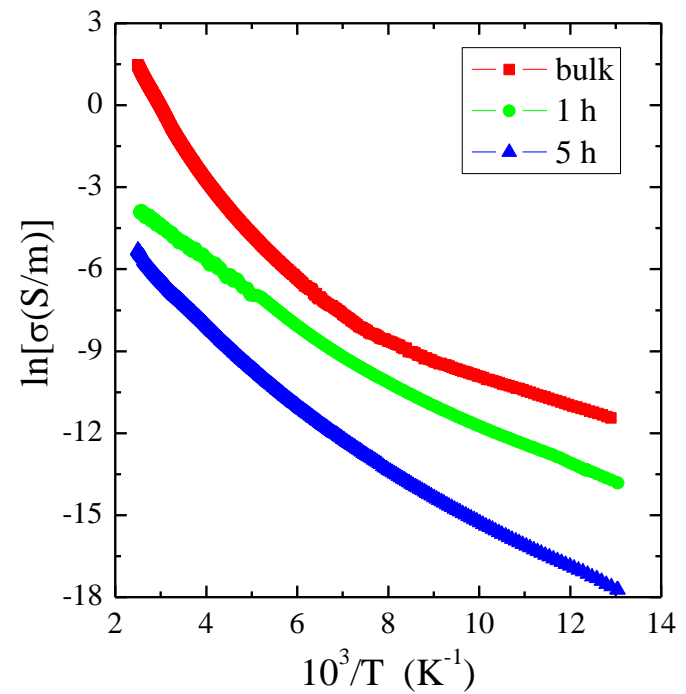

Figure 3. Electrical conductivity ( $\ln \sigma$ ) vs. reciprocal temperature $10^{3} / \mathrm{T}$ measured for $\mathrm{ZnCr}_{2} \mathrm{Se}_{4}$ single crystal and nanocrystals after 1 and $5 \mathrm{~h}$ of milling.

Temperature measurements of thermoelectric power (Figure 4) showed the dominance of holes in the bulk material (well-known in the literature $[7,28]$ ) as well as in the sample after one hour of milling, and the dominance of electrons in the sample after five hours of milling. In the latter, the electron conductivity may have been due to the appearance of donor (anion) vacancies and structural defects during the formation of small particles as a result of crushing. In the materials of the spinel structure, strong ionic bonds existed between cations and anions. The appearance of a non-zero value of the electrical conductivity in spinels might have been caused by both the existence of mixed valence bands and ion vacancies [29]. In the $\mathrm{ZnCr}_{2} \mathrm{Se}_{4}$ spinel, which is a $p$-type semiconductor, chromium ions were 
in the $3 d t_{2 \mathrm{~g}}$ ground state and did not form a band of mixed valence. Therefore, after a longer milling time, there was a predominance of anion vacancies over cationic ones, which was manifested by a change in the type of conduction from $p$ to $n$.

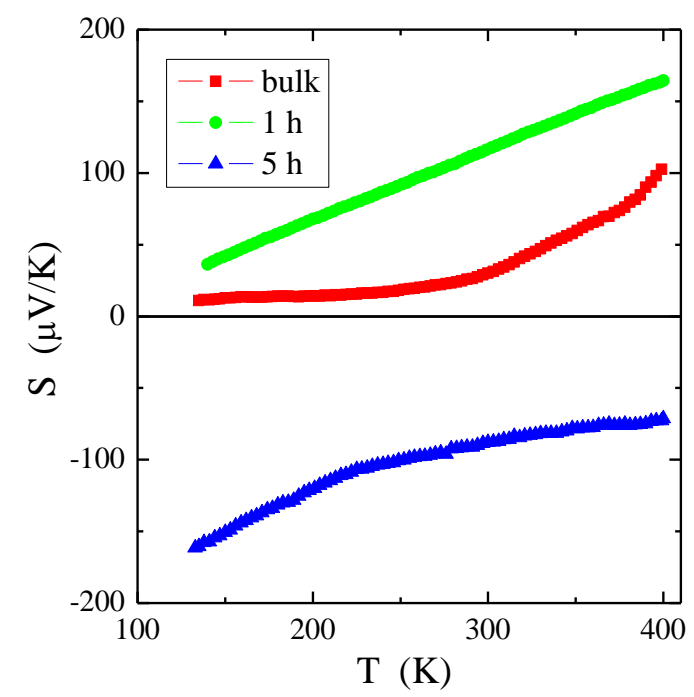

Figure 4. Thermoelectric power $S$ vs. temperature $T$ measured for $\mathrm{ZnCr}_{2} \mathrm{Se}_{4}$ single crystal and nanocrystals after 1 and $5 \mathrm{~h}$ of milling.

\subsection{Magnetic Properties}

The temperature dependence of dc magnetic susceptibility, both ZFC $\left(\chi_{\mathrm{ZFC}}\right)$ and FC $\left(\chi_{\mathrm{FC}}\right)$, showed AFM order for bulk material and nanocrystals after 1 and $3 \mathrm{~h}$ of milling with the Néel temperatures of 18 , 20, and $20 \mathrm{~K}$, respectively (Figure 5, Table 2). At the same time, the positive value of the paramagnetic Curie-Weiss temperature $(\theta)$, characteristic of the short-range FM interactions, varied from 92 (for bulk), then 25 (for $1 \mathrm{~h}$ ) to $48 \mathrm{~K}$ (for $3 \mathrm{~h}$ ). The nanocrystal after $5 \mathrm{~h}$ of milling showed unexpectedly ferrimagnetic (FIM) long-range interactions visible in the deviation of the curve of the inverse magnetic

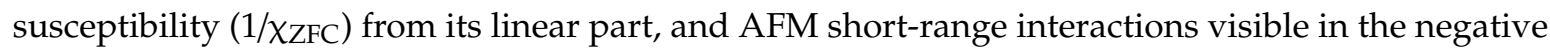
value of paramagnetic Curie-Weiss temperature of $\theta=-201 \mathrm{~K}$ (Table 2), as well as the spin-glass-like (SG) behavior, evidenced by the splitting of the ZFC and FC magnetic susceptibility below the freezing temperature of $T_{\mathrm{f}}=20 \mathrm{~K}$ (Figure 5). The confirmation of the existence of the SG state was also the shift of the ac magnetic susceptibility peak towards the higher frequencies (Figure 6) that is described by the Vogel-Fulchel law [30]. However, this shift was not exactly monotonous with frequency, hence the Vogel-Fulchel law cannot be fit reliably. Usually, the $\mathrm{ZnCr}_{2} \mathrm{Se}_{4}$ single crystals described in the literature have a positive and high Curie-Weiss temperature in the range of $\theta=90-115 \mathrm{~K}[6,7,9]$, just like the single crystal in this study.

Table 2. Magnetic parameters of $\mathrm{ZnCr}_{2} \mathrm{Se}_{4}$ nanospinels.

\begin{tabular}{|c|c|c|c|c|c|c|c|c|c|}
\hline $\begin{array}{l}t \\
\text { (h) }\end{array}$ & $\begin{array}{l}d \\
(\mathrm{~nm})\end{array}$ & $\begin{array}{l}C \\
(\mathrm{emu} \cdot \mathrm{K} / \mathrm{mol})\end{array}$ & $\begin{array}{l}T_{\mathrm{N}} \\
(\mathrm{K})\end{array}$ & $\begin{array}{l}\theta \\
(\mathrm{K})\end{array}$ & $\begin{array}{l}\mu_{\text {eff }} \\
\left(\mu_{B} / \text { f.u. }\right)\end{array}$ & $\begin{array}{l}M_{(2 \mathrm{~K})} \\
\left(\mu_{\mathrm{B}} / \mathrm{f} . \mathrm{u} .\right)\end{array}$ & $\begin{array}{l}J_{1} \\
(\mathrm{~K})\end{array}$ & $\begin{array}{l}J_{2} \\
(\mathrm{~K})\end{array}$ & Ref. \\
\hline- & bulk & 4.082 & 21 & 90 & 5.714 & 6.0 & -1.65 & 1.28 & [9] \\
\hline- & bulk & 3.377 & 18 & 92 & 5.197 & 5.125 & -1.17 & 1.22 & this paper \\
\hline 1 & 25 & 8.841 & 20 & 25 & 8.409 & 4.328 & -2.58 & 0.71 & this paper \\
\hline 3 & 2.5 & 5.273 & 20 & 48 & 6.494 & 3.401 & -2.20 & 0.90 & this paper \\
\hline 5 & 2 & 4.611 & $T_{\mathrm{f}}=20 \mathrm{~K}$ & -201 & 6.073 & 2.358 & $J_{\mathrm{SG}}=33.3 \mathrm{~K}$ & & this paper \\
\hline
\end{tabular}

$t$ is the milling time; $d$ is the crystallite size; $C$ is the Curie constant; $T_{N}, T_{\mathrm{f}}$, and $\theta$ are the Néel, freezing, and Curie-Weiss temperatures, respectively; $\mu_{\text {eff }}$ is the effective magnetic moment; $M$ is the magnetization at $2 \mathrm{~K} ; J_{1}$ and $J_{2}$ are the superexchange integrals for the first two coordination spheres; and $J_{\mathrm{SG}}$ is the exchange constant of the spin-glass system. For comparison, magnetic parameters of $\mathrm{ZnCr}_{2} \mathrm{Se}_{4}$ bulk single crystal from the literature [9] were taken. 

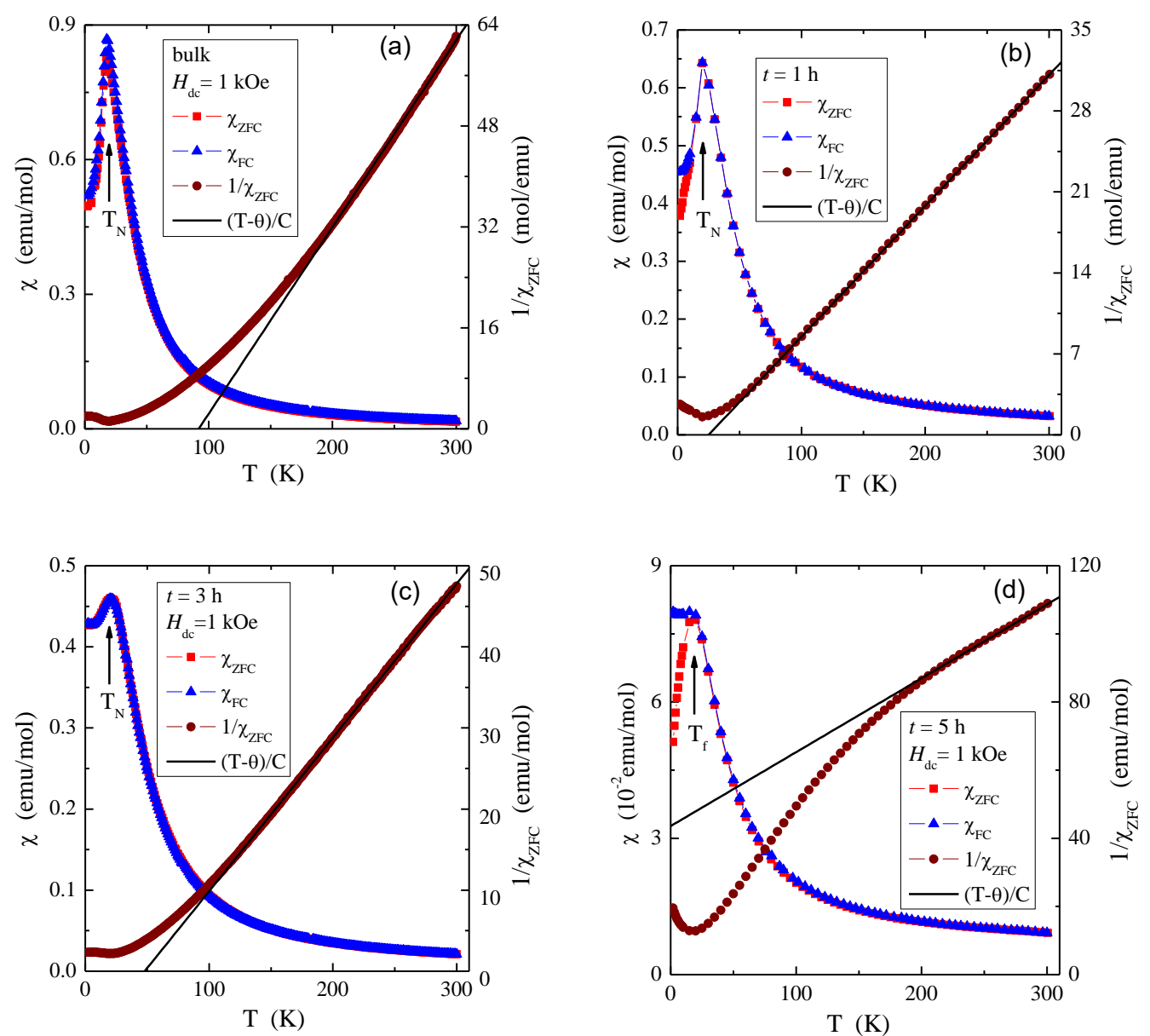

Figure 5. Zero-field-cooled (ZFC) and field-cooled (FC) magnetic susceptibility $\chi$ vs. temperature $T$ at $H_{\mathrm{dc}}=1 \mathrm{kOe}$ for $\mathrm{ZnCr}_{2} \mathrm{Se}_{4}$ single crystal (a) and nanocrystals after $1 \mathrm{~h}(\mathbf{b}), 3 \mathrm{~h} \mathrm{(c)}$, and $5 \mathrm{~h}$ (d) of milling. $T_{\mathrm{N}}$ and $T_{\mathrm{f}}$ are the Néel and freezing temperatures, respectively.

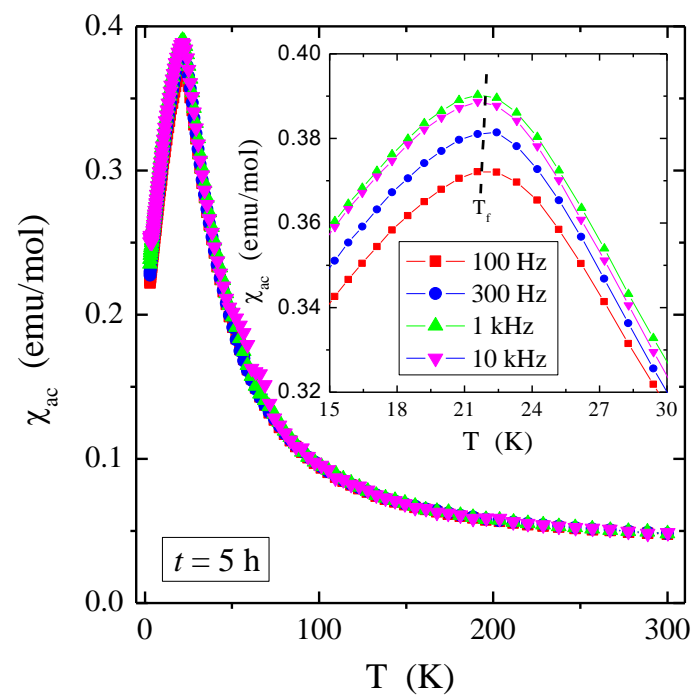

Figure 6. In-phase component of ac magnetic susceptibility $\chi_{\mathrm{ac}}$ vs. temperature $T$ at $H_{\mathrm{ac}}=2$ Oe recorded at different frequencies and after $5 \mathrm{~h}$ of milling. Inset: $\chi_{\mathrm{ac}}(T)$ magnification in the range up to $30 \mathrm{~K}$.

The reduction in crystallite size strongly affected both the value and the sign of this temperature (Table 2). All nanocrystals had significantly higher values of the effective magnetic moment, compared to the theoretical value of $\mu_{\text {eff }}=5.477 \mu_{\mathrm{B}} /$ f.u., in which the $\mathrm{Cr}^{3+}$ ions were in the $3 d t_{2 \mathrm{~g}}$ high-spin 
configuration, and the experimental values of 5.197 and $5.714 \mu_{\mathrm{B}} / \mathrm{f} . \mathrm{u}$. for the single crystal under study, and taken from [9], respectively (Table 2). It may indicate that, in the studied spinel nanoparticles, magnetic dipoles or magnetic cluster structure had formed.

The crystallite size also affected the magnetic interactions described by the superexchange integrals (Table 2). For single crystal and nanocrystals after 1 and $3 \mathrm{~h}$ of milling, the superexchange integral for the first coordination sphere $\left(J_{1}\right)$ is negative and becomes more negative for nanocrystals. In turn, the superexchange integral for the second coordination sphere $\left(J_{2}\right)$ is positive and becomes less positive for nanocrystals. In this case, the $J_{1}$ integral represents the antiferromagnetic long-range interactions, while the $J_{2}$ integral represents the short-range ferromagnetic ones. As a consequence, for nanocrystals after $5 \mathrm{~h}$ of milling, i.e., for the sample with the smallest crystallite size (Table 1 ), the spin-glass state whose exchange integral is large, i.e., $J_{\mathrm{SG}}=33.3 \mathrm{~K}$ (Table 2), was observed. For comparison, $J_{\mathrm{SG}}=$ $73.3 \mathrm{~K}$ for spin-glass-like behavior in single-crystalline $\mathrm{Cu}_{0.44} \mathrm{In}_{0.48} \mathrm{Cr}_{1.95} \mathrm{Se}_{4}$ spinel was found [31].

The magnetic isotherms of the single crystal and the nanocrystals after 1,3, and $5 \mathrm{~h}$ of milling are displayed in Figure 7. With the reduction of crystallite size, magnetization at $2 \mathrm{~K}$, and in the magnetic field of 75 , kOe decreases from $5.125 \mu_{\mathrm{B}} / \mathrm{f}$.u. (for bulk) to $2.358 \mu_{\mathrm{B}} /$ f.u. (for $5 \mathrm{~h}$ ), and the magnetic isotherms move away from the state of saturation. On magnetic isotherms at $2 \mathrm{~K}$ and in the magnetic field of $10 \mathrm{kOe}$, the inflection points are clearly visible, which are characteristic of the first critical field associated with the transition from the helical phase to the conical phase (metamagnetic threshold) for single crystal and nanocrystals after 1 and $3 \mathrm{~h}$ of milling. As the milling time increases, we observe the shift of the first critical field towards smaller fields and its disappearance for a $5 \mathrm{~h}$ sample. A similar shift is observed for $\mathrm{M}-\mathrm{H}$ hysteresis (not visible in Figure 7), as well as, e.g., in $\mathrm{NiO}$ nanocrystals [32]. The second critical field associated with the transition from the magnetic cone structure to the ferromagnetic phase was not observed for any of the studied samples in the magnetic field up to $75 \mathrm{kOe}$. It is usually perceived in a magnetic field of $65 \mathrm{kOe}$ [9] when the magnetic isotherm reaches saturation.

\subsection{Specific Heat}

Figure 8 shows the specific heat measured up to $40 \mathrm{~K}$ for the single crystal (8a) and up to $300 \mathrm{~K}$ for nanocrystal after $5 \mathrm{~h}$ of milling $(8 \mathrm{~b})$. The specific heat $C(T)$ measured for the single crystal shows at the temperature $T_{N} \lambda$-shape peak characteristic of the second-type paramagnetic-antiferromagnetic order. In the temperature range $T>T_{N}$ the specific heat is usually expresses by phonon contribution $C(T)=\beta T^{3}$. However, in the case of monocrystalline $\mathrm{ZnCr}_{2} \mathrm{Se}_{4}$, the $C(T) \sim T^{3}$ behavior is limited only to narrow temperature range $T_{\mathrm{N}}<T<28 \mathrm{~K}$, because of presence of spin fluctuations [11] that modify the lattice contribution to specific heat. In this narrow temperature range $\beta=0.00045 \mathrm{~J} / \mathrm{mol} \mathrm{K}^{4}$. For $N=7$ atoms in formula unit, $\beta=N(12 / 5) \pi^{4} R \theta_{\mathrm{D}}$ gives the Debye temperature $\theta_{\mathrm{D}} \approx 311 \mathrm{~K}$. For the nanocrystalline material, we also fitted the Debye model to the $C$ (T) data (as is shown in Figure $8 b$ ) in the wide temperature range, assuming that the spin fluctuations are removed in nano-grained material. The obtained fit parameters were: Debye temperature $\theta_{D}=290 \mathrm{~K}$ and the number of atoms $n_{D}=8.38$. The number of atoms is significantly larger than the expected 7 for the $\mathrm{ZnCr}_{2} \mathrm{Se}_{4}$ formula unit. The simple explanation of this phenomenon can be provided on the basis of the model published in [30], where the authors have shown that, for the nanoparticles, the specific heat is larger than for the bulk solid. The inset presents the fraction of the number of atoms on the surface $N$ to the total number of atoms $n$, versus the ratio of specific heat measured for nanoparticles $C_{n}$ to the specific heat measured for the bulk solid lattice $C_{b}$. In our case, such an estimation shows that $32 \%$ of atoms are on the surface, which clearly confirms that our sample was milled down to a few $\mathrm{nm}$ in size. In Figure 8a, a clear peak at $T_{\mathrm{N}}$ in the specific heat curve of a single crystal is observed, but no peak is visible in specific heat for the nanocrystal after $5 \mathrm{~h}$ of milling (Figure $8 \mathrm{~b}$ ), which suggests that, for such small nanoparticles, no long range magnetic order was present. There is a spread in the size of nanoparticles. Despite the fact that most of them are in the nm range, a small fraction can be larger and exhibit magnetic ordering, which is visible in the ac magnetic susceptibility. 

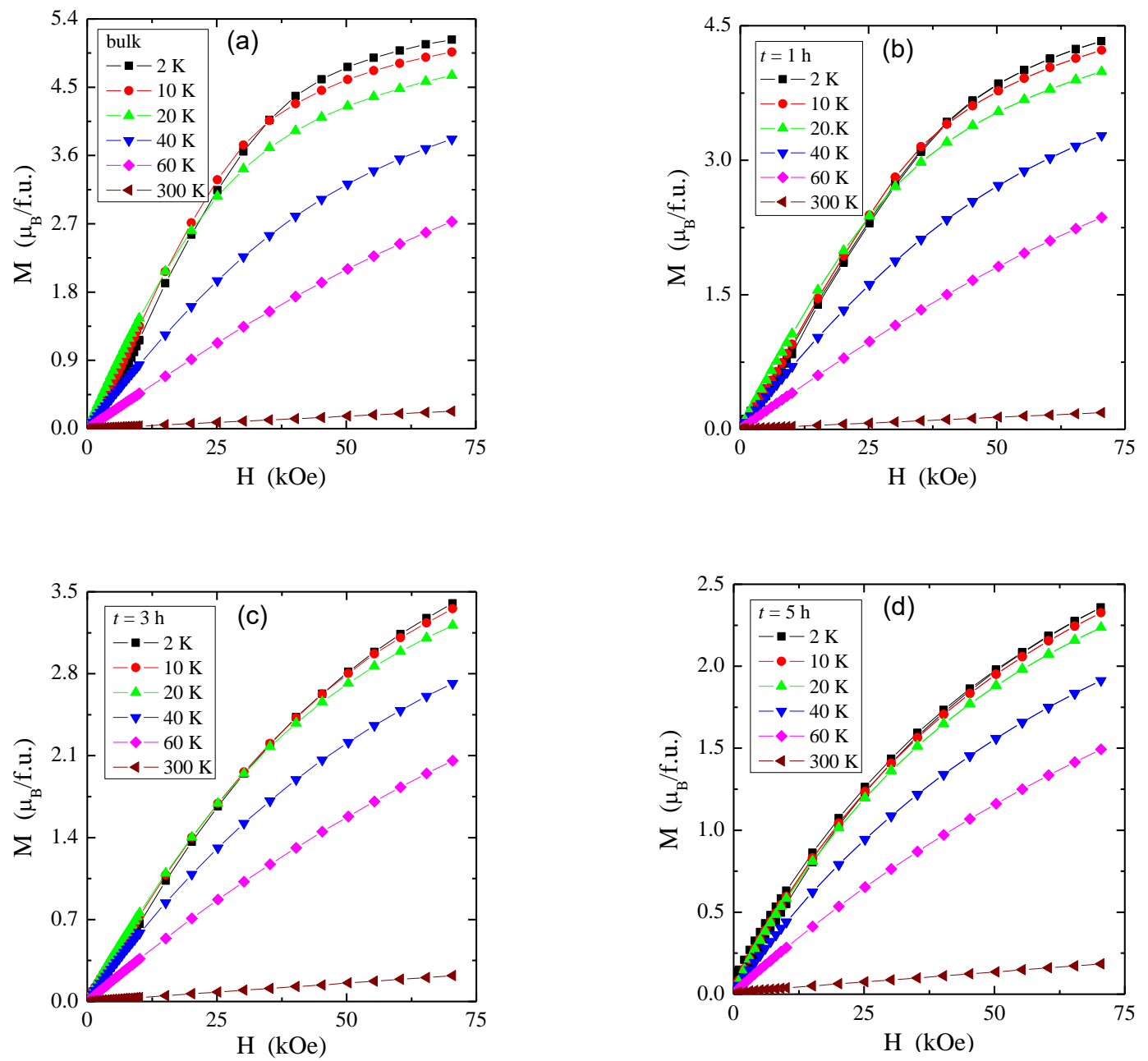

Figure 7. Magnetization $M$ vs. magnetic field $H$ at 2, 10, 20, 40, 60, and $300 \mathrm{~K} \mathrm{kOe} \mathrm{for} \mathrm{ZnCr}_{2} \mathrm{Se}_{4}$ single crystal (a) and nanocrystals after $1 \mathrm{~h} \mathrm{(b)}, 3 \mathrm{~h}$ (c), and $5 \mathrm{~h}$ (d) of milling.

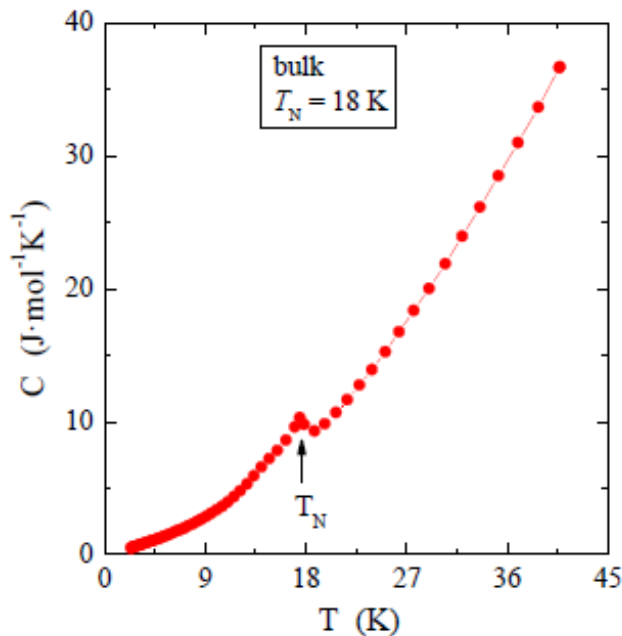

(a)

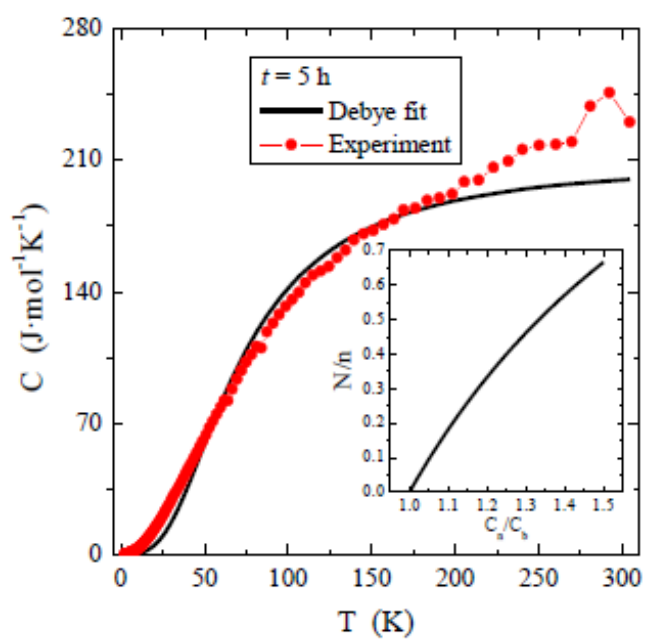

(b)

Figure 8. Specific heat $C$ vs. temperature $T$ in zero-magnetic field measured for the single crystal (a) and for nanocrystals after $5 \mathrm{~h}$ of milling (b). This sum contains electronic, antiferromagnetic, and lattice contribution. In the right panel, the solid line represents the Debye fit. In the inset we show: $N / n$ vs. $C_{\mathrm{n}} / C_{\mathrm{b}}$, where $N$ is the number of atoms on the surface, $n$ is the total number of atoms, $C_{\mathrm{n}}$ is the specific heat measured for nanoparticles, and $C_{\mathrm{b}}$ is the specific heat measured for the bulk solid lattice. 


\section{Conclusions}

The nanocrystals were obtained using the high-energy ball-milling method from the $\mathrm{ZnCr}_{2} \mathrm{Se}_{4}$ single crystal after 1,3, and $5 \mathrm{~h}$ of milling, whose crystallite sizes were $25.2,2.5$, and $2 \mathrm{~nm}$, respectively. Structural, electrical, magnetic, and specific heat measurements showed that all samples had a spinel structure, were $p$-type semiconductors with less milling time, and $n$-type with a higher one. With a decrease in crystallite size, the magnetic order changed from antiferromagnetic for bulk material and nanocrystals after 1 and $3 \mathrm{~h}$ of milling to the spin-glass state for the nanocrystal after $5 \mathrm{~h}$ of milling. The spin-glass-like behavior was derived from a broad peak of dc magnetic susceptibility, a splitting of the zero-field-cooling and field-cooling susceptibilities, and from the shift of the freezing temperature towards the higher frequency of the ac susceptibility curves. The spin-glass-like system was also confirmed by the large exchange constant of $33.3 \mathrm{~K}$, which was additionally accompanied by the lack of a peak on the specific heat curve, suggesting a disappearance of the structural transition.

In summary, decreasing the spinel monocrystal crystallite resulted in a change in magnetic order from AFM to SG, an increase in AFM long-range interactions, and weakening of FM short-range ones that finally led to a strong competition of FIM and AFM interactions in the spin-glass sample with the smallest crystallite size.

Author Contributions: Conceptualization, E.M., M.K., and T.G.; methodology, E.M., M.K., and T.G.; validation, E.M.; formal analysis, M.K., T.G., and A.G.; investigation, E.M., M.K., A.G., J.G., M.O., B.S., and J.P.; resources, E.M. and A.G.; writing—original draft preparation, E.M., M.K., T.G., and A.Ś,; writing—review and editing, E.M. and M.K.; visualization, M.K. and T.G.; supervision, E.M. and M.K.; project administration, E.M. and M.K.

Funding: This research received no external funding.

Acknowledgments: This work is partly supported by the Ministry of Scientific Research and Information Technology (Poland) and funded from Science Resource: No.1S-0300-500-1-05-06.

Conflicts of Interest: The authors declare no conflicts of interest.

\section{References}

1. Snyder, G.J.; Caillat, T.; Fleurial, J.P. Thermoelectric properties of chalcogenides with the spinel structure. Mater. Res. Innov. 2001, 5, 67-73. [CrossRef]

2. Groń, T.; Krajewski, A.; Duda, H.; Urbanowicz, P. Influence of nonstoichiometry on the lattice excitations in the $\mathrm{Zn}_{\mathrm{x}} \mathrm{Cu}_{\mathrm{y}} \mathrm{Cr}_{\mathrm{z}} \mathrm{Se}_{4}$ p-type spinel ferromagnetic conductors. Physica B 2006, 373, 245-252. [CrossRef]

3. Mazur, S.; Groń, T.; Jendrzejewska, I. Influence of spin arrangement on thermopower in $\mathrm{Zn}_{\mathrm{x}} \mathrm{Cu}_{\mathrm{y}} \mathrm{Cr}_{\mathrm{z}} \mathrm{Se}_{4}$ spinels. J. Alloy Compd. 2009, 480, 19-22. [CrossRef]

4. Shannon, R.D. Revised effective ionic radii and systematic studies of interatomic distances in halides and chalcogenides. Acta Cryst. 1976, A 32, 751-767. [CrossRef]

5. Philipsborn, H. Chalcogenide spinels and alternative structures. Z. Kristallogr. Cryst. Mater. 1971, 133, 464-472. [CrossRef]

6. Plumier, R. Étude par diffraction de neutrons de l'antiferromagnétisme hélicoïdal du spinelle $\mathrm{ZnCr}_{2} \mathrm{Se}_{4}$ en présence d'un champ magnétique. J. Phys. (Paris) 1966, 27, 213-219. [CrossRef]

7. Lotgering, F.K. Proceedings of the International Conference on Magnetism: Held at Nottingham, Sept. 1964; Institute of Physics (IOP): London/Bristol, UK, 1965; p. 533.

8. Kleinberger, R.; Kouchkovsky, R. Étude radiocristallographique á basse température du spinelle $\mathrm{ZnCr}_{2} \mathrm{Se}_{4}$. Phys. Solides. Comp. Rend. Acad. Sci. (Paris) 1966, 262, 628-630.

9. Hemberger, J.; von Nidda, H.A.K.; Tsurkan, V.; Loidl, A. Large magnetostriction and negative thermal expansion in the frustrated antiferromagnet $\mathrm{ZnCr}_{2} \mathrm{Se}_{4}$. Phys. Rev. Lett. 2007, 98, 147203. [CrossRef]

10. Malicka, E.; Waśkowska, A.; Mydlarz, T.; Kaczorowski, D. Structural and magnetic properties of single-Crystalline spinel systems $\mathrm{ZnCr}_{2-\mathrm{x}} \mathrm{Al}_{x} \mathrm{Se}_{4}(\mathrm{x}=0.15$ and 0.23). J. Alloy Compd. 2007, 440, 1-5. [CrossRef]

11. Malicka, E.; Groń, T.; Ślebarski, A.; Gagor, A.; Pacyna, A.W.; Sitko, R.; Goraus, J.; Mydlarz, T.; Heimann, J. Specific heat and magnetic susceptibility of single-crystalline $\mathrm{ZnCr}_{2} \mathrm{Se}_{4}$ spinels doped with $\mathrm{Ga}$, In and Ce. Mater. Chem. Phys. 2011, 131, 142-150. [CrossRef] 
12. Malicka, E.; Waśkowska, A.; Heimann, J.; Mydlarz, T.; Sitko, R.; Kaczorowski, D. Structural and magnetic properties of $\mathrm{Zn}_{1-\mathrm{x}} \mathrm{Sb}_{\mathrm{x}} \mathrm{Cr}_{2-\mathrm{x} / 3} \mathrm{Se}_{4}(\mathrm{x}=0.11,0.16$ and 0.20$)$ single crystals. J. Solid State Chem. 2008, 181, 1970-1976. [CrossRef]

13. Jendrzejewska, I.; Zajdel, P.; Goryczka, T.; Goraus, J.; Kita, A.; Mydlarz, T. Influence of covalency and anion polarization on magnetic and electronic properties of $\mathrm{ZnCr}_{2-\mathrm{x}} \mathrm{Ni}_{\mathrm{x}} \mathrm{Se}_{4}$. J. Alloy Compd. 2012, 520, 153-157. [CrossRef]

14. Jendrzejewska, I.; Groń, T.; Kusz, J.; Żelechower, M.; Maciążek, E.; Ślebarski, A.; Fijałkowski, M. Spin-glass-like behaviour in tin doped $\mathrm{ZnCr}_{2} \mathrm{Se}_{4}$ single crystals. J. Alloys Compd. 2015, 635, 238-244. [CrossRef]

15. Maciążek, E.; Malicka, E.; Karolus, M.; Panek, J.; Stokłosa, Z.; Groń, T.; Gudwański, A.; Sawicki, B. Magnetic characteristics of $\mathrm{CuCr}_{2} \mathrm{~S}_{4}$ nanospinels obtained by mechanical alloying and heat treatment. IEEE Trans. Magn. 2017, 53, 2400205.

16. Williamson, G.K.; Hall, W.H. X-ray line broadening from filed aluminium and wolfram. Acta Metall. 1953, 1, 22-31. [CrossRef]

17. Young, R.A. The Rietveld Method; Oxford University Press: Oxford, UK, 1993; Chapter 6.

18. McCusker, L.B.; von Dreele, R.B.; Cox, D.E.; Louer, D.; Scardi, P. Rietveld refinement guidelines. J. Appl. Crystallogr. 1999, 32, 36-50. [CrossRef]

19. Karolus, M.; Łagiewka, E. Crystallite size and lattice strain in nanocrystalline Ni-Mo alloys studied by Rietveld Refinement. J. Alloy Compd. 2004, 367, 235-238. [CrossRef]

20. Karolus, M. Applications of Rietveld refinement in Fe-B-Nb alloy structure studies. J. Mater. Process. Technol. 2006, 175, 246-250. [CrossRef]

21. Groń, T.; Krok-Kowalski, J.; Duda, H.; Mydlarz, T.; Gilewski, A.; Walczak, J.; Filipek, E.; Bärner, K. Metamagnetism in the $\mathrm{Cr}_{2} \mathrm{~V}_{4-\mathrm{x}} \mathrm{Mo}_{\mathrm{x}} \mathrm{O}_{13+0.5 \mathrm{x}}$ solid solutions. Phys. Rev. B 1995, 51, 16021-16024. [CrossRef]

22. Krok-Kowalski, J.; Groń, T.; Warczewski, J.; Mydlarz, T.; Okońska-Kozłowska, I. Ferrimagnetism and metamagnetism in $\mathrm{Cd}_{1-\mathrm{x}} \mathrm{Cu}_{\mathrm{x}} \mathrm{Cr}_{2} \mathrm{~S}_{4}$ spinels. J. Magn. Magn. Mater. 1997, 168, 129-138. [CrossRef]

23. Groń, T.; Pacyna, A.W.; Malicka, E. Influence of temperature independent contribution of magnetic susceptibility on the Curie-Weiss law. Solid State Phenom. 2011, 170, 213-218. [CrossRef]

24. Holland, W.E.; Brown, H.A. Application of the Weiss molecular field theory to the B-site spinel. Phys. Status Solidi A 1972, 10, 249-253. [CrossRef]

25. Derrida, B. Random-energy model: Limit of a family of disordered models. Phys. Rev. Lett. 1980, 45, 79-82. [CrossRef]

26. Derrida, B. Random-energy model: An exactly solvable model of disordered systems. Phys. Rev. B 1981, 24, 2613-2626. [CrossRef]

27. Binder, K.; Young, A.P. Spin glasses: Experimental facts, theoretical concepts, and open questions. Rev. Mod. Phys. 1986, 58, 801-976. [CrossRef]

28. Groń, T.; Duda, H.; Warczewski, J. Influence of the valence of the substituted cations on the electrical properties of the magnetically modulated spinels $\mathrm{Zn}_{1-\mathrm{x}} \mathrm{A}_{\mathrm{x}} \mathrm{Cr}_{2} \mathrm{Se}_{4}\left(\mathrm{~A}=\mathrm{Cu}, \mathrm{Ga}_{2 / 3}\right)$. Phys. Rev. B 1990, 41, 12424-12431. [CrossRef] [PubMed]

29. Groń, T. Influence of vacancies and mixed valence on the transport processes in solid solutions with the spinel structure. Philos. Mag. B 1994, 70, 121-132. [CrossRef]

30. Tholence, J.L. On the frequency dependence of the transition temperature in spin glasses. Solid State Commun. 1980, 35, 113-117. [CrossRef]

31. Duda, H.; Maciążek, E.; Groń, T.; Mazur, S.; Pacyna, A.W.; Waśkowska, A.; Mydlarz, T.; Gilewski, A. Spin-glass-like behaviour in single-crystalline $\mathrm{Cu}_{0.44} \operatorname{In}_{0.48} \mathrm{Cr}_{1.95} \mathrm{Se}_{4}$. Phys. Rev. B 2008, 77, 035207-8. [CrossRef]

32. Yi, J.B.; Ding, J.; Feng, Y.P.; Peng, G.W.; Chow, G.M.; Kawazoe, Y.; Liu, B.H.; Yin, J.H.; Thongmee, S. Size-dependent magnetism and spin-glass behavior of amorphous NiO bulk, clusters, and nanocrystals: Experiments and first-principles calculations. Phys. Rev. B 2007, 76, 224402. [CrossRef]

(C) 2019 by the authors. Licensee MDPI, Basel, Switzerland. This article is an open access article distributed under the terms and conditions of the Creative Commons Attribution (CC BY) license (http://creativecommons.org/licenses/by/4.0/). 